\title{
Kualitas Pelayanan dan Fasilitas Mempengaruhi Kepuasan Konsumen di Bandar Udara Notohadi Negoro Jember
}

\author{
Arif Fakhrudin \\ ${ }^{1}$ Manajemen Transportasi, Sekolah Tinggi Teknologi Kedirgantaraan \\ Jalan Parangtritis Km. 4,5 Druwo, Bangunharjo, Sewon, Bantul, Indonesia
}

Email: ariffakhrudin21@gmail.com

\begin{abstract}
ABSTRAK
Transportasi merupakan sarana yang berperan sebagai penunjang, pendorong dan penggerak. Sehingga masyarakat lebih selektif dalam pemilihan sesuatu, karena masyarakat menginginkan pelayanan dan fasilitas yang melebihi harapan konsumen. Penelitian ini bertujuan untuk mengetahui pengaruh kualitas pelayanan dan fasilitas terhadap kepuasan konsumen di Bandar Udara Notohadi Negoro Jember. Penelitian ini menggunakan dua variabel independen yaitu kualitas pelayanan dan fasilitas dengan satu dependen yaitu kepuasan konsumen. Setelah dilakukan tinjauan pustaka dan hipotesis, data dalam penelitian ini dikumpulkan melalui penyebaran kuesioner dengan jumlah 100 responden yang menggunakan jasa Bandar Udara Notohadi Negoro Jember sebagai sampel penelitian. Teknik pengambilan sampel yang digunakan adalah purposive sampling. Metode analisis data yang digunakan adalah analisis kuantitatif yaitu uji validitas, uji reliabilitas, analisis regresi linear berganda, uji $t$ dan uji f serta uji koefisien determinan. Hasil penelitian ini menunjukkan bersifat valid dan reliabel. Pada uji hipotesis kualitas pelayanan dan fasilitas berpengaruh signifikan positif terhadap kepuasan konsumen. Hasil uji koefisien determinasi pada penelitian ini diperoleh nilai determinan 0,168 yang berarti bahwa besarnya pengaruh variabel kualitas pelayanan dan fasilitas terhadap variabel kepuasan konsumen adalah $16,8 \%$.
\end{abstract}

\begin{abstract}
Transportation is a means that acts as a support, impetus and driving force. So that people are more selective in choosing something, because people want services and facilities that exceed consumer expectations. This study aims to determine the effect of service quality and facilities on customer satisfaction at Notohadi Negoro Airport, Jember. This study use two independent variables, namely the quality service and facility with a dependent costumer satisfaction. After a literature review and a hypothesis, the data for this study was collected through questionnaires with a total of 100 respondens who used the services of Notohadi Negoro Jember Airport as a research sample. The sampling technique used was purposive sampling. The methods of data analysis used quantitative analysis, validity test, reliablity test, the multiple regression analysis, $t$ test, $f$ test, and test of determining factor. The result of this study indicate that they are valid and reliable. In the hypothesis test, quality service and facility have a significant positive effect on customer satisfaction. The result of the test of the determining coefficient in this study obtained a determining value of 0,168 which means that the amplitude of the influence of the variables quality service and facility on the satisfaction variable is $16,8 \%$.
\end{abstract}

Keyword: Costumer Satisfaction; Facility; Quality Service 


\section{PENDAHULUAN}

Masyarakat saat ini cenderung lebih memilih transportasi yang cepat, efektif dan efisien. Transportasi merupakan sarana yang berperan sebagai penunjang, pendorong dan penggerak. Sehingga masyarakat lebih selektif dalam pemilihan sesuatu, karena masyarakat menginginkan pelayanan dan fasilitas yang melebihi harapan konsumen. Ketersediaan pelayanan jasa penerbangan yang sesuai dengan kebutuhan masyarakat, seperti pelayanan dan fasilitas di dalam bandara yang harus ada (Moenir, 2010).

Strategi untuk mencari pelanggan baru dengan mempertahankan pelanggan yang sudah ada dan menciptakan kelebihan khusus adalah strategi kualitas layanan. Kualitas pelayanan yang baik akan mempengaruhi kepuasan, dimana konsumen merasa dihargai (Pantilu et al., 2018). Terkait pelayanan yang dikutip dalam buku manajemen pelayanan umum merupakan proses pemenuhan kebutuhan dimana fokus pada layanan yang diberikan kepada konsumen untuk mendapatkan kepuasan dalam memenuhi permintaan (Moenir, 2010).

Menurut Parasuraman dalam Tjiptono (2005), kualitas pelayanan merupakan ukuran atau trend secara keseluruhan dalam hal nilai pelayanan. Pemahaman ini didasarkan pada tiga sumber utama: 1) kinerja, 2) prediksi kualitas layanan dan, 3) evaluasi kualitas. Menurut Supranto, (2016) kualitas pelayanan merupakan suatu pencapaian yang harus diraih dimana tindakan tersebut tidak terlihat dan bisa menghilang.. Menurut Zeithaml dan Bitner (2006), untuk mengukur kualitas pelayanan dengan menggunakan kuesioner. Teknik SERVQUAL, diantaranya adalah: tangible, reliability, responsiveness, assurance, empathy. Kualitas pelayanan berfokus pada pemenuhan kebutuhan, ketepatan waktu untuk memenuhi harapan konsumen (William dan Purba, 2020).

Penelitian yang dilakukan oleh Widuyah (2012) diketahui bahwa kualitas pelayanan berpengaruh positif, kuat, serta signifikan terhadap kepuasan nasabah pada Bank Muamlat Indonesia Cabang Cirebon. Penelitian yang dilakukan oleh Yunus dan Budiyanto (2014) bahwa kualitas pelayanan mempengaruhi kepuasan pelanggan dalam menggunakan jasa Narita Hotel Surabaya. Penelitian yang dilakukan Adawia et al. (2017) dimana kualitas pelayanan mempengaruhi kepuasan konsumen PT Kereta Commuter Indonesia. Berdasarkan uraian tersebut, maka hipotesis kesatu $\left(\mathrm{H}_{1}\right)$ :

\section{H1: Ada pengaruh kualitas pelayanan terhadap kepuasan konsumen di Bandar Udara Notohadi Negoro Jember.}

Fasilitas merupakan sesuatu yang bersifat fisik yang ditawarkan kepada konsumen. Contohnya kelayakan tempat duduk di ruang tunggu, kelayakan $\mathrm{AC}$, kelayakan toilet serta kelayakan loby keberangkatan, pelayanan dan kinerja petugas bandara, misalnya petugas 
bandara seperti Avsec (Aviation Security) melakukan pengecekan boarding pass dan barang di Screening Check Point maupun mengarahkan penumpang di ruang tunggu keberangkatan, sehingga konsumen dapat melakukan penerbangan dengan aman dan nyaman. Tempat ruang tunggu keberangkatan yang disediakan antara lain ruang tunggu umum dan ruang tunggu vip (Tjiptono, 2005). Fasilitas merupakan sesuatu yang berbentuk fisik atau terlihat, yang diberikan perusahaan guna memberikan kenyamanan kepada konsumen yang dimana sebagai tanda bahwa telah sesuai dengan harapan konsumen atau sudah melampaui harapan konsumen (Pantilu et al., 2018).

Fasilitas adalah objek penting untuk menaikan tingkat kepuasan seperti kenyamanan pelanggan (William da Purba, 2020). Fasilitas adalah bagian paling utama dalam pemasaran jasa, karena sebuah produk yang disampaikan kepada konsumen sangat memerlukan sebuah fasilitas pendukung untuk membantu dalam menyampaikan produk mereka (Santosa, 2007). Fasilitas adalah suatu bentuk fisik yang mempunyai fungsi meningkatkan suatu nilai produk atau layanan yang diberikan (Andari, 2017). Fasilitas merupakan salah satu alat ukur dari sebuah pelayanan, dimana mempengaruhi kepuasan pelanggan. Karena dengan adanya fasilitas, hal tersebut dapat membantu pelanggan dalam beraktifitas dan merasa nyaman (Srijani, 2017).

Penelitian yang dilakukan oleh Aji (2011) menyatakan bahwa fasilitas mempunyai pengaruh signifikan terhadap kepuasan pasien pada klinik As Syifa Bekasi. Penelitian yang dilakukan oleh Susilo et al. (2015) menunjukkan terdapat pengaruh fasilitas belajar terhadap kepuasan siswa SMK Satrya Budi Karang Rejo. Penelitian yang dilakukan oleh Adawia et al. (2017) dimana variabel fasilitas mempengaruhi variabel kepuasan konsumen PT Kereta Commuter Indonesia. Berdasarkan uraian tersebut, maka hipotesis kedua $\left(\mathrm{H}_{2}\right)$ :

\section{$H_{2}$ : Ada pengaruh fasilitas terhadap kepuasan konsumen di Bandar Udara Notohadi Negoro Jember.}

Menurut Schnaars dalam Tjiptono (2005), dengan menciptakan para pelanggan yang merasa puas adalah tujuan dari suatu bisnis. Kepuasan pelanggan terhadap perusahaan muncul disebabkan dari suatu pengalaman bertransaksi dengan perusahaan tersebut dan hal itu memberikan kesan positif pelanggan yang dimana berdampak pada kelangsungan perusahaan dalam jangka panjang (Ermawati, Sudiro dan Khusniyah, 2016). Muktiono (2014) menyatakan seorang pelanggan akan merasa puas atau tidak ketika pengalaman dalam menggunakan produk, hal tersebut dapat mempengaruhi sikap setelahnya. Untuk meningkatkan kepuasan pelanggan yang dapat mempengaruhi loyalitas pelanggan dengan 
cara mengurangi pengetahuan konsumen terhadap harga, mengurangi kemerosotan pasar, dikuranginya biaya pengelolaan akibat bertambahnya jumlah pengguna, meningkatkan dampak periklanan, meningkatkan nilai bisnis perusahaan (Soegoto, 2013).

Menurut Kotler (2010a), kepuasan adalah rasa bahagia atau sebaliknya yang dialami konsumen dimana muncul ketika membandingkan antara kinerja produk dengan harapan konsumen. Selanjutnya, Endarwita (2013) mengungkapkan bahwa kepuasan konsumen menciptakan retensi konsumen dimana biaya untuk mencari konsumen lebih banyak biayanya, dimana mempertahankan konsumen yang sudah ada akan lebih rendah biayanya. Prasetyo (2013) menyatakan bahwa puas atau sebaliknya adalah tanggapan menurut konsumen terhadap penilaian yang telah mereka lakukan antara keinginan sebelumnya dan hasil berdasarkan pengalaman dalam mengkonsumsi sebuah produk.

Penelitian yang dilakukan oleh Rahman (2013) dimana kualitas pelayanan dan fasilitas berpengaruh terhadap kepuasan konsumen pada Pemancingan Ngrembel Asri Gunung Pati Semarang secara simultan. Penelitian yang dilakukan Mardiyani, (2013) dimana kualitas pelayanan dan fasilitas mempengaruhi kepuasan pelanggan pada SPBU 44.594.10 ds. Wedekan Kec. Bangsari Jepara secara simultan. Penelitian yang dilakukan oleh Adawia et al. (2017) dimana kualitas pelayanan dan fasilitas mempengaruhi kepuasan konsumen pada PT. KCI secara simultan. Berdasarkan uraian tersebut, maka hipotesis ketiga $\left(\mathrm{H}_{3}\right)$ :

\section{H3: Ada pengaruh kualitas pelayanan dan fasiltas terhadap kepuasan konsumen di Bandar Udara Notohadi Negoro Jember.}

Hal ini melatarbelakangi, dimana peneliti ingin menganalisis faktor-faktor yang mempengaruhi kepuasan konsumen dan memfokuskan kepada dua variabel penting yaitu kualitas pelayanan dan fasilitas di Bandar Udara Notohadi Negoro Jember. Berdasarkan uraian tersebut, maka peneliti ingin mengetahui pengaruh kualitas pelayanan dan fasilitas terhadap kepuasan konsumen di Bandar Udara Notohadi Negoro Jember secara parsial dan simultan. Hubungan antar variabel penelitian ini ditunjukkan pada Gambar 1 dibawah ini:

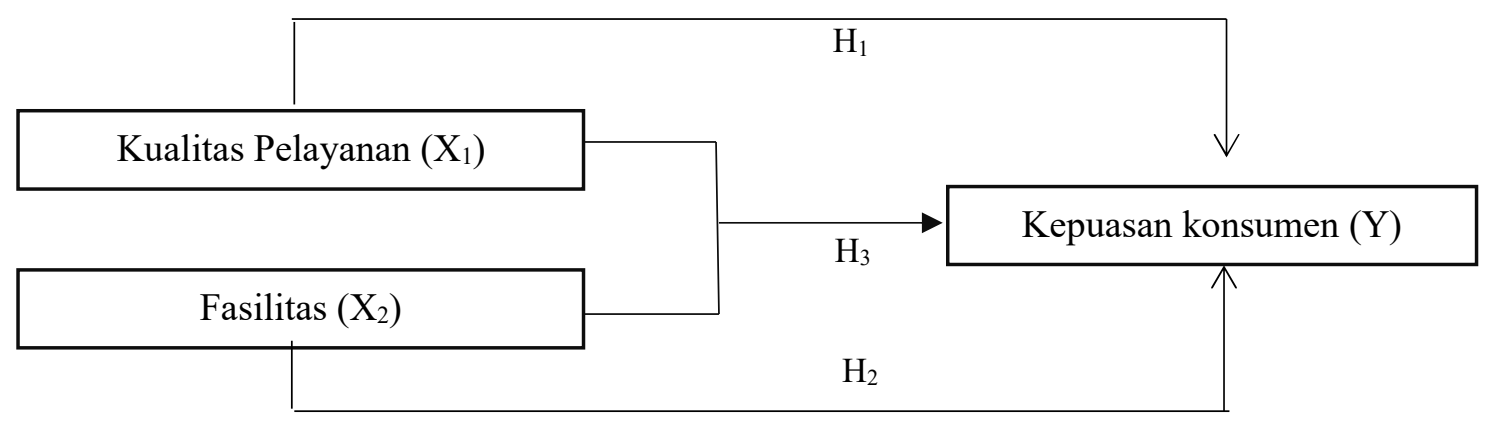

Gambar 1. Kerangka Penelitian 


\section{METODE PENELITIAN}

Penelitian ini merupakan penelitian kuantitatif dengan metode survey. Untuk mengumpulkan data primer dengan menggunakan kuesioner. Penelitian ini mengkaji pengaruh kualitas pelayanan $\left(\mathrm{X}_{1}\right)$ dan fasilitas $\left(\mathrm{X}_{2}\right)$ terhadap kepuasan konsumen $(\mathrm{Y})$. Teknik pengambilan sampel dalam penelitian ini yaitu purposive sampling, dimana kriteria sampel tersebut yaitu konsumen yang sudah pernah menggunakan layanan jasa dan fasilitas di Bandar Udara Notohadi Negoro Jember. Definisi operasional, indikator dan skala pengukuran disajikan dalam rincian pada Tabel 1.

Tabel 1. Definisi Operasional, Indikator, dan Skala Pengukuran

\begin{tabular}{|c|c|c|c|c|}
\hline No & Variabel & Definisi Operasional & Indikator & $\begin{array}{c}\text { Skala } \\
\text { Pengukuran }\end{array}$ \\
\hline 1 & $\begin{array}{l}\text { Kualitas } \\
\text { Pelayanan }\end{array}$ & $\begin{array}{l}\text { Kualitas pelayanan } \\
\text { adalah setiap tindakan } \\
\text { atau kegiatan yang } \\
\text { sifatnya menawarkan } \\
\text { kepada orang lain, yang } \\
\text { tidak terlihat dan tidak } \\
\text { mengakibatkan suatu } \\
\text { kepemilikan. }\end{array}$ & $\begin{array}{l}\text { 1. Tangible (berwujud). } \\
\text { 2. Reliability } \\
\text { (kehandalan). } \\
\text { 3. Responsiveness } \\
\text { (ketanggapan). } \\
\text { 4. Assurance (jaminan). } \\
\text { 5. Empathy (empati). }\end{array}$ & $\begin{array}{l}\text { Diukur dengan } \\
\text { menggunakan } \\
\text { skala Likert 1-5. }\end{array}$ \\
\hline 2 & Fasilitas & $\begin{array}{l}\text { Fasilitas adalah sarana } \\
\text { untuk melancarkan dan } \\
\text { memudahkan } \\
\text { pelaksanaan fungsi. }\end{array}$ & $\begin{array}{l}\text { 1. Perencanaan spasial. } \\
\text { 2. Perencanaan ruang. } \\
\text { 3. Perlengkapan. } \\
\text { 4. Tata cahaya. } \\
\text { 5. Pesan-pesan grafis. } \\
\text { 6. Unsur pendukung. }\end{array}$ & $\begin{array}{c}\text { Diukur dengan } \\
\text { menggunakan } \\
\text { skala Likert 1-5. }\end{array}$ \\
\hline 3 & $\begin{array}{l}\text { Kepuasan } \\
\text { Konsumen }\end{array}$ & $\begin{array}{l}\text { Kepuasan konsumen } \\
\text { merupakan rasa } \\
\text { bahagia atau rasa } \\
\text { kecewa dari seseorang, } \\
\text { dimana seseorang } \\
\text { tersebut telah } \\
\text { membandingkan antara } \\
\text { kinerja dengan harapan. }\end{array}$ & $\begin{array}{l}\text { 1. Penyediaan layanan } \\
\text { yang baik. } \\
\text { 2. Cepat menyelesaikan } \\
\text { pekerjaan. } \\
\text { 3. Mampu mengetahui } \\
\text { harapan dan dapat } \\
\text { menduga hal yang } \\
\text { harus dilakukan secara } \\
\text { cepat. } \\
\text { 4. Mampu memberikan } \\
\text { perhatian. }\end{array}$ & $\begin{array}{c}\text { Diukur dengan } \\
\text { menggunakan } \\
\text { skala Likert 1-5. }\end{array}$ \\
\hline
\end{tabular}

Sumber: Tjiptono, (2005)

\section{HASIL DAN PEMBAHASAN}

Responden dalam penelitian ini yaitu penumpang di Bandar Udara Notohadi Negoro Jember. Jumlah sampel dalam penelitian ini, mengacu pada Roscoe dalam Sugiyono (2010) dimana sampel yang diambil antara 30 sampai 500 sampel, sudah mencukupi untuk suatu 
penelitian. Kuesioner yang digunakan peneliti sebanyak 100.

Karakteristik responden disajikan dalam Tabel 2 dimana mayoritas responden adalah perempuan sebanyak 55\%. Terkait usia, mayoritas responden berusia pada rentang 17-20 tahun sebanyak 34\% dan mayoritas responden sebagai mahasiswa/pelajar sebesar $46 \%$.

Tabel 2. Karakteristik Responden

\begin{tabular}{llcc}
\hline $\begin{array}{c}\text { Karekteristik } \\
\text { Responden }\end{array}$ & Kriteria & $\begin{array}{c}\text { Jumlah } \\
(\mathbf{n = 1 0 0 )}\end{array}$ & Persentase \\
\hline Jenis Kelamin & Laki-Laki & 45 & $45 \%$ \\
\hline \multirow{2}{*}{ Usia } & Perempuan & 55 & $55 \%$ \\
\hline & $17-20$ tahun & 34 & $34 \%$ \\
\hline \multirow{3}{*}{ Pekerjaan } & $21-24$ tahun & 33 & $33 \%$ \\
\hline & $>25$ tahun & 33 & $33 \%$ \\
\hline & Mahasiswa/Pelajar & 46 & $46 \%$ \\
\hline & Swasta & 13 & $13 \%$ \\
\hline
\end{tabular}

Sumber: Data primer telah diolah

Uji validitas memperlihatkan, variabel kualitas pelayanan dinyatakan semuanya valid dan uji reliabilitas diperoleh nilai koefisien sebesar 0,796 dimana variabel kualitas pelayanan dinyatakan reliabel. Variabel fasilitas juga dinyatakan semuanya valid dan uji reliabilitas variabel fasilitas menunjukkan bahwa nilai koefisien sebesar 0,790 dimana variabel fasilitas juga reliabel. Pengukuran variabel kepuasan konsumen dinyatakan semuanya valid dan uji reliabilitasnya menghasilkan nilai koefisien sebesar 0,769 dimana variabel kepuasan konsumen dinyatakan reliabel.

Berdasarkan analisis regresi linear berganda pada Tabel 3, variabel kualitas pelayanan memiliki t-hitung sebesar 2,785 dengan nilai signifikansi sebesar 0,018. Hasil tersebut menunjukkan bahwa nilai t-hitung lebih besar dari t-tabel 1,98 dan nilai signifikansi lebih kecil dari pada 0,05. Dengan demikian, variabel kualitas pelayanan berpengaruh signifikan terhadap kepuasan konsumen di Bandar Udara Notohadi Negoro Jember secara parsial, sehingga $\mathrm{H}_{1}$ dapat diterima.

Hasil penelitian ini didukung dengan penelitian Pantilu et al. (2018) diketahui bahwa kualitas pelayanan mempunyai pengaruh secara signifikan terhadap kepuasan pelanggan pada pada Warunk Bendito. Hasil tersebut juga selaras dengan penelitian yang dilakukan oleh Endang dan Cholidah (2017), hasil penelitian diketahui bahwa kualitas pelayanan berpengaruh signifikan terhadap kepuasan penumpang di terminal Rajekwesi Bojonegoro. 
Hasil penelitian yang dilakukan William dan Purba (2020) dimana kualitas pelayanan memiliki pengaruh positif terhadap kepuasan pelanggan pada Bengkel Mazda di Kota Batam. Hasil ini mendukung penelitian sebelumnya oleh Arianto (2018) dengan hasil simpulan dimana mempunyai pengaruh yang positif dan signifikan dari kualitas pelayanan terhadap kepuasan pengunjung. Penelitian yang dilakukan oleh Maydiana (2019), Pane (2017), Pratiwi (2018), dan Irfan (2019), dimana hasil penelitian mereka menunjukkan bahwa kualitas pelayanan mempunyai pengaruh terhadap kepuasan konsumen secara parsial.

Berdasarkan analisis regresi linear berganda pada Tabel 3, menunjukkan bahwa t-hitung variabel fasilitas sebesar 2,688 dengan nilai signifikansi sebesar 0,009. Hasil tersebut membuktikan bahwa nilai t-hitung lebih besar dari pada t-tabel 1,98 dan nilai signifikansi lebih kecil daripada 0,05. Dengan demikian, variabel fasilitas memberikan pengaruh signifikan secara parsial terhadap kepuasan konsumen di Bandar Udara Notohadi Negoro Jember, sehingga $\mathrm{H}_{2}$ dapat diterima.

Dari hasil tersebut, penelitian ini mendukung penelitian Pantilu et al. (2018). Hasil uji hipotesis bahwa fasilitas berpengaruh terhadap kepuasan pelanggan pada Warung Bendito. Hasil penelitian Maryati dan NE.Husda (2020), bahwa fasilitas berpengaruh signifikan terhadap kepuasan pelanggan pada Holiday Hotel di Kota Batam. Hasil penelitian yang dilakukan William dan Purba (2020) dimana fasilitas mempunyai pengaruh terhadap kepuasan pelanggan pada Bengkel Mazda di Kota Batam. Artinya, semakin banyak fasilitas yang tersedia di perusahaan maka akan menaikkan tingkat kepuasan pelanggan. Hasil penelitian Harfika dan Abdullah (2017) bahwa variabel fasilitas berpengaruh terhadap kepuasan pasien. Penelitian Maydiana (2019), Pane (2017), Pratiwi (2018), dan Irfan (2019), dimana hasil penelitian mereka menunjukkan bahwa fasilitas berpengaruh terhadap kepuasan konsumen secara parsial.

Tabel 3. Hasil Analisis Regresi Linear Berganda

\begin{tabular}{lcccccc}
\hline \multirow{2}{*}{ Model } & \multicolumn{2}{c}{$\begin{array}{c}\text { Unstandardized } \\
\text { Coefficients }\end{array}$} & $\begin{array}{c}\text { Standardized } \\
\text { Coefficients }\end{array}$ & t & \multirow{2}{*}{ Sig. } \\
\cline { 2 - 5 } & $\mathbf{B}$ & Std. Error & Beta & & \\
\hline (Constant) & 20,047 & 3,882 & - & 6,505 & 0,000 \\
\hline Kualitas Pelayanan $\left(\mathrm{X}_{1}\right)$ & 0,398 & 0,144 & 0,268 & 2,785 & 0,018 \\
\hline Fasilitas $\left(\mathrm{X}_{2}\right)$ & 0,438 & 0,168 & 0,250 & 2,688 & 0,009 \\
\hline
\end{tabular}

Sumber: Data primer telah diolah

Berdasarkan hasil Uji F, diketahui F-hitung sebesar 9,844 dengan tingkat signifikansi 0,000. Dengan demikian diketahui bahwa hipotesis ketiga diterima karena F-hitung $(9,844)>$ 
F-tabel $(3,13)$ dengan tingkat signifikansi $0,000<0,05$. Dimana kualitas pelayanan dan fasilitas berpengaruh secara simultan terhadap kepuasan konsumen di Bandar Udara Notohadi Negoro Jember, sehingga $\mathrm{H}_{3}$ dapat diterima.

Penelitian ini sejalan dengan penelitian yang dilakukan Bailia et al. (2014) dimana hasil penelitian ini menunjukkan bahwa secara simultan kualitas pelayanan dan fasilitas mempunyai pengaruh terhadap kepuasan konsumen pada Warung-Warung Makan Lamongan di Kota Manado. Penelitian yang dilakukan oleh Puspita dan Santoso (2018) yakni secara simultan kualitas pelayanan dan fasilitas pendukung berpengaruh terhadap kepuasan pelanggan Stasiun Lempuyangan Yogyakarta. Hasil penelitian yang dilakukan William dan Purba (2020) dimana secara bersamaan variabel kualitas pelayanan dan fasilitas ini berpengaruh terhadap kepuasan pelanggan pada Bengkel Mazda di Kota Batam. Penelitian ini didukung oleh penelitian sebelumnya Sinaga (2017) dengan hasil kualitas pelayanan dan fasilitas terdapat pengaruh terhadap kepuasan tamu Hotel Harmoni. Penelitian yang dilakukan oleh Maydiana (2019), Pane (2017), Pratiwi (2018), dan Irfan (2019) dimana hasil penelitian mereka menunjukkan bahwa secara simultan kualitas pelayanan dan fasilitas berpengaruh terhadap kepuasan konsumen.

Tabel 4. Hasil Uji F (Simultan)

\begin{tabular}{cccccc}
\hline Model & $\begin{array}{c}\text { Sum of } \\
\text { Squares }\end{array}$ & $\boldsymbol{d f}$ & $\begin{array}{c}\text { Mean } \\
\text { Square }\end{array}$ & $\boldsymbol{F}$ & Sig. \\
\hline Regression & 286,577 & 2 & 143,363 & 9,844 & $.000^{\mathrm{a}}$ \\
Residual & 411,983 & 97 & 14,577 & & \\
\hline Total & 698,560 & 99 & & & \\
\hline
\end{tabular}

Sumber: Data primer telah diolah

Dari uji koefisien determinasi $\left(\mathrm{R}^{2}\right)$ dalam penelitian ini ditunjukkan dengan angka $\mathrm{R}^{2}$ (R-square) sebesar 0,168 atau 16,8\%. Hasil ini menunjukkan dimana variabel kualitas pelayanan dan fasilitas di Bandar Udara Notohadi Negoro Jember, dapat menjelaskan variasi pada variabel kepuasan konsumen sebesar 16,8\%, sedangkan sisanya sebesar 83,2\% dijelaskan oleh variabel lain.

Tabel 5. Hasil Uji Koefisien Determinasi

\begin{tabular}{cccc}
\hline $\mathbf{R}$ & R-square & Adjusted $\mathbf{R}$-square & Std. Error of the Estimate \\
\hline 0,411 & 0,168 & 0,153 & 3,815 \\
\hline
\end{tabular}

Sumber: Data primer telah diolah 


\section{KESIMPULAN DAN SARAN}

Berdasarkan hasil perhitungan statistik dalam uji parsial, dimana variabel kualitas pelayanan berpengaruh terhadap kepuasan konsumen di Bandar Udara Notohadi Negoro Jember atau $\mathrm{H}_{1}$ dapat diterima. Hasil statistik berikutnya juga menunjukkan bahwa fasilitas berpengaruh terhadap kepuasan konsumen di Bandar Udara Notohadi Negoro Jember atau $\mathrm{H}_{2}$ diterima. Dan hasil statistik berikutnya juga menunjukkan bahwa kualitas pelayanan dan fasilitas berpengaruh secara simultan terhadap kepuasan konsumen di Bandar Udara Notohadi Negoro Jember atau $\mathrm{H}_{3}$ diterima. Dari hasil koefisien determinasi menunjukkan bahwa kualitas pelayanan dan fasilitas dapat menjelaskan variasi yang terjadi pada variabel kepuasan konsumen di Bandar Udara Notohadi Negoro Jember sebesar 16,8\% dan sisanya sebesar $83,2 \%$ dijelaskan oleh variabel lain di luar model penelitian.

Dari hasil tersebut, pihak manajemen Bandar Udara Notohadi Negoro Jember perlu meningkatkan kinerja layanan jasa penerbangannya. Upaya peningkatan kualitas pelayanan dan fasilitas, seperti layanan berkualitas dan fasilitas yang ada di bandara perlu mendapatkan perhatian serius. Pada penelitian selanjutnya perlu memperbanyak jumlah sampel dan penambahan jumlah variabel.

\section{REFERENCES}

Adawia, P. R., Azizah, A., dan Endriastuty, Y. (2017). Kepuasan Konsumen Kereta Api Commuter Line (Studi Kasus Commuter Line Arah Cikarang ke Jakarta Kota). Sebatik, 1(7), 87-95.

Aji, W. K. (2011). Analisis Pengaruh Kualitas Pelayanan, Harga dan Fasilitas terhadap Kepuasan Pasien (Studi pada Pasien Klinik As Syifa di Kab. Bekasi). Universitas Diponegoro.

Andari, C. L. S. (2017). Pengaruh Kualitas Pelayanan dan Fasilitas terhadap Kepuasan Pengunjung (Studi Kasus Pengunjung The Sila's Agrotourism). Universitas Sanata Dharma.

Arianto, N. (2018). Pengaruh Kualitas Pelayanan terhadap Kepuasan dan Loyalitas Pengunjung dalam Menggunakan Jasa Hotel Rizen Kedaton Bogor. Jurnal Pemasaran Kompetitif, 1(2), 83-101. https://doi.org/10.32493/jpkpk.v1i2.856.

Bailia, J. F. T., Soegoto, A. S., dan Loindong, S. S. R. (2014). Pengaruh Kualitas Produk, Harga dan Lokasi terhadap Kepuasan Konsumen pada Warung-Warung Makan Lamongan di Kota Manado. Jurnal EMBA, 2(3), 1768-1780.

Endang, E., dan Cholidah, L. N. (2017). Pengaruh Fasilitas dan Kualitas Pelayanan terhadap Kepuasan Penumpang di Terminal Rajekwesi Bojonegoro. Jurnal Teknika, 9(2), 911915. https://doi.org/10.30736/teknika.v9i2.55.

Endarwita. (2013). Pengaruh Kualitas Produk dan Kualitas Pelayanan terhadap Kepuasan dan Loyalitas Nasabah Tabungan Bank BRI Cabang Simpang Empat. Apresiasi Ekonomi, 1(3), 167-180.

Ermawati, P. W., Sudiro, A., dan Khusniyah, N. (2016). Pengaruh Kesadaran Merek dan Asosiasi Merek terhadap Ekuitas Merek pada Pelanggan Hypermarket di Kota Malang. 
Jurnal Aplikasi Manajemen, $\quad$ 14(2), 373-386. https://doi.org/10.18202/jam23026332.14.2.19.

Ginting, P. (2005). Pemasaran Pariwisata. USU Press.

Harfika, J., dan Abdullah, N. (2017). Pengaruh Kualitas Pelayanan dan Fasilitas terhadap Kepuasan Pasien pada Rumah Sakit Umum Kabupaten Aceh Barat Daya. Balance, 14(1), 44-56.

Hasan, S. (2009). Pengaruh Kualitas Layanan, Citra, Nilai dan Kepuasan terhadap Loyalitas Pasien (Studi pada Industri Rumah Sakit di Kota Makassar). Aplikasi Manajemen, 8(1), 256-263.

Irfan, A. M. (2019). Pengaruh Kualitas Pelayanan, Harga dan Fasilitas yang Diberikan Kenari Waterpark Bontang terhadap Tingkat Kepuasan Pelanggan. Al-Infaq: Jurnal Ekonomi Islam, 9(2), 82. https://doi.org/10.32507/ajei.v9i2.451.

Kotler, P. (2010a). Manajemen Pemasaran. Erlangga.

Kotler, P. (2010b). Prinsip - Prinsip Pemasaran (Sembilan). PT Indeks Gramedia.

Maharani, A. dhiah. (2010). Analisis Pengaruh Kepercayaan dan Kepuasan terhadap Loyalitas Nasbah tabungan Bank Mega Semarang. Diponegoro Journal of Management. https://doi.org/10.1002/j.2161-4296.1970.tb00024.x.

Mardiyani, M. S. (2013). Analisis Pengaruh Kualitas Pelayanan dan Fasilitas terhadap Kepuasan Pelanggan. Diponegoro Journal of Management. https://doi.org/10.37673/jmb.v2i2.516.

Maryati, F., dan NE.Husda. (2020). Pengaruh Fasilitas dan Kualitas Pelayanan terhadap Kepuasan Pelanggan pada Holiday Hotel di Kota Batam. Jurnal Magisma, 8(1), 19-26.

Moenir, A. S. (2010). Manajemen Pelayanan Umum di Indonesia. Bumi Aksara.

Muktiono, K. V. (2014). Pengaruh Kualitas Pelayanan Inti dan Kualitas Pelayanan Periferal terhadap Kepuasan Pelanggan serta Dampaknya terhadap Minat Word Of Mouth pada Bengkel Pt. Nasmoco Gombel Semarang. Diponegoro Journal of Management.

Pane, A. M. (2017). Pengaruh Kualitas Layanan, Fasilitas, Harga, dan Lokasi terhadap Kepuasan Konsumen di Zona Futsal. Journal of Chemical Information and Modeling, 53(9), 1689-1699. https://doi.org/10.1017/CBO9781107415324.004.

Pantilu, D., Koleangan, R. A. M., dan Roring, F. (2018). Pengaruh Kualitas Pelayanan, Harga dan Fasilitas terhadap Kepuasan Pelanggan pada Warunk Bendito Kawasan Megamas Manado. Jurnal EMBA: Jurnal Riset Ekonomi, Manajemen, Bisnis Dan Akuntansi, 6(4), 3723-3732. https://doi.org/10.35794/emba.v6i4.21898.

Prasetyo, W. B. (2013). Pengaruh Kualitas Pelayanan, Kepercayaan dan Kepuasan terhadap Loyalitas Pelanggan (Studi pada Swalayan Luwes Purwodadi ). Jurnal Manajemen Pemasaran, 1-13.

KPratiwi, M. (2018). Pengaruh Kualitas Pelayanan, Fasilitas dan Harga terhadap Kepuasan Konsumen di Penginapan Lebar Daun Palembang. Univeristas Islam Negeri Raden Fatah Palembang.

Priyatno, D. (2010). Teknik Mudah dan Cepat Melakukan Analisis Data Penelitian dengan SPSS dan Tanya Jawab Ujian Pendadaran. Gaya Media.

Puspita, R. M., dan Santoso, S. (2018). Pengaruh Kualitas Pelayanan dan Fasilitas Pendukung terhadap Kepuasan Pelanggan Stasiun Lempuyangan Yogyakarta. Eksis: Jurnal Riset Ekonomi dan Bisnis, 13(1), 69-80. https://doi.org/10.26533/eksis.v13i1.145.

Rahman, D. N. (2013). Pengaruh Kualitas Pelayanan, Fasilitas, Persepsi Harga dan Lokasi Terhadap Kepuasan Konsumen pada Pemancingan Ngrembel Asri Gunungpati Semarang. Universitas Negeri Semarang.

Santosa, D. D. K. (2007). Analisis Kepuasan Konsumen terhadap Fasilitas Ruang Tunggu Terminal Bandara Adisutjipto. Universitas Sanata Dharma.

Sinaga, R. (2017). Pengaruh Kualitas Pelayanan dan Fasilitas terhadap Kepuasan Tamu 
Hotel Harmoni Batam.

Soegoto, A. S. (2013). Persepsi Nilai dan Kepercayaan terhadap Kepuasan dan Dampaknya terhadap Loyalitas Konsumen. Jurnal Riset Ekonomi, Manajemen, Bisnis dan Akuntansi, 1(3), 1271-1283.

Sugiyono, P. (2010). Metode Penelitian Bisnis. Alfabeta.

Supranto, J. (2016). Pengukuran Tingkat Kepuasan Pelanggan untuk Menaikkan Pangsa Pasar. PT Asdi Mahasatya.

Susilo, H. A., Lie, D., Butarbutar, M., dan Efendi. (2015). Pengaruh Fasilitas Belajar Terhadap Kepuasan Siswa pada SMK Satrya Budi Karang Rejo. Jurnal MAKER, 1(1), $14-21$.

Tjiptono, F. (2005). Service Marketing: Esensi \& Aplikasi. Penerbit Marknesis.

Widuyah, W. (2012). Pengaruh Kualitas Pelayanan dan Kelengkapan Fasilitas terhadap Kepuasan Nasabah pada Bank Muamalat Indonesia Cabang Cirebon (Institut Agama Islam Negri Syekh Nurjati Cirebon). Resources, 2(10). https://doi.org/10.1007/s11837012-0378-1.

William, dan Purba, T. (2020). Kualitas Pelayanan dan Fasilitas terhadap Kepuasan Pelanggan pada Bengkel Mazda di Kota Batam. Jurnal Riset Ekonomi, Manajemen, Bisnis dan Akuntansi, 8(1), 1987-1996.

Yunus, dan Budiyanto. (2014). Pengaruh Kualitas Pelayanan dan Fasilitas terhadap Kepuasan Pelanggan. Jurnal Ilmu \& Riset Manajemen, 3(12), 1-20.

Zeithaml, V.A. and Bitner, M. . (2006). Services Marketing: Integrating Customer Focus Across the Firm. McGraw Hill. 